\title{
Achievement motivation and its relation to nurses' decision making beliefs, ability, and job burnout at obstetric and gynecological departments
}

\author{
Rasha Ibrahim El Sayed ${ }^{* 1}$, Maha Ramadan Ali $^{2}$ \\ ${ }^{1}$ Nursing Administration, Faculty of Nursing, Port-Said University, Egypt \\ ${ }^{2}$ Maternity, Obstetric and Gynecological Nursing, Faculty of Nursing, Port-Said University, Egypt
}

Received: July 9, 2017

DOI: $10.5430 /$ cns.v5n4p42
Accepted: August 2, 2017

URL: https://doi.org/10.5430/cns.v5n4p42
Online Published: August 14, 2017

\begin{abstract}
Objective: Challenges in todays' work environment require professional competent nurses not only educated well but being creative, have a desire to achieve success, able to work under pressure, and accomplish the organizational and personal goals. Aim of the study: The study was aimed at assessing nurses' achievement motivation and its relation to their decision making beliefs, ability, and job burnout at obstetrics and gynecological departments.

Methods: Setting: This study was conducted in Port Said governorate, Egypt. Design: A descriptive co-relational research design was used. Subjects: Consisted of all staff nurses working in all obstetric and gynecologic departments affiliated to ministry of health, with a total number of 75 nurse. Tools: Achievement Motivation Scale (AMS), decision making beliefs, decision making ability questionnaire, and job burnout scale.

Results: The study revealed that nurses' age ranged between 22 and 60 years. The majority of nurses were holding a nursing diploma. More than three quarters of nurses have achievement motivation and having well beliefs about decision making. The total mean score for decision making ability was 74.2 \pm 7.3. Nearly half of nurses evaluated in this study have burnout.

Conclusions: A significant correlation between achievement motivation and decision making ability while no statistically significant correlation was detected between achievement motivation and both of decision making beliefs and total score of job burnout.

Recommendations: Strategies for the preservation and promotion of achievement motivation is very important. In addition, this study recommended in the different nursing departments to identify and influence achievement motivation among nursing staff.
\end{abstract}

Key Words: Achievement motivation, Decision making ability, Decision making beliefs, Job burnout

\section{INTRODUCTION}

\subsection{Achievement motivation}

Achievement motivation was defined by Zenzen ${ }^{[1]}$ as the comparison of performance with others and against certain standards, it is a combination of two personality variables; tendency to approach success and tendency to avoid fail- ure. According to Esteem \& Physiological, ${ }^{[2]}$ achievement motivation is characterized by the fact that the individual is responsible for the outcome (success or failure), anticipates results, have some degree of uncertainty or risk; views the strength of an individual's goal-directed tendency as jointly determined by his motives, by his expectations about the

\footnotetext{
*Correspondence: Rasha Ibrahim El Sayed; Email: rashamoheb@gmail.com; Address: Nursing Administration, Faculty of Nursing, Port-Said University, Egypt.
} 
consequences of his actions, and by the incentive values of expected consequences.

Achievement motivation is the striving to increase or to keep as high as possible, one's own capabilities in all activities in which a standard of excellence is thought to apply and where the execution of such activities can, therefore either succeed or fail. Achievement motivation is a subjective and internal psychological drive, enabling individuals to pursue work they perceive to be valuable and prompting them to reach their goals. ${ }^{[3]}$

\subsection{Decision-making}

Nurses should be able to use decision-making skills to provide safe and effective nursing care. Nurses are providing direct care and therefore have the greatest opportunity to apply their knowledge to meet patients' needs. Additionally, nurses are usually the first professionals to observe rapid deterioration in a patient's health status. Consequently, it is the nurse's interpretation of events that will determine subsequent action. Decision-making is a process that nurses use to gather information about patients, evaluate it and make judgments result in the provision of nursing care. Staff nurse decisional involvement is associated with positive patient outcomes including a higher quality of patient care, lower patient mortality, fewer complications and lower levels of job strain and burnout. ${ }^{[4]}$

Obstetric and gynecologic nurses, regularly made decisions on direct patient care, which includes providing basic nursing care, emotional and psychological support, and health education. In practice, the nurse is required to make rapid decisions or choices under conditions of uncertainty. These choices are influenced by the subjective and objective information and data available to the nurse at the time of the decision. ${ }^{[5]}$ The credibility of the source and the weight given to the information available will determine if it is considered essential, critical, irrelevant, or discounted. ${ }^{[6,7]}$ The nurse's integration of the selected information, knowledge base, and perception of the problem provides a basis for decision making. ${ }^{[8]}$

\subsection{Nurses burnout}

In $1974,{ }^{[9]}$ Freudenberg coined the term "burnout" to describe workers' reactions to the chronic work stress involving numerous direct interactions with people. Burnout remains significant concerns in nursing, affecting both individuals and organizations. ${ }^{[10]}$ Burnout is typically conceptualized as a syndrome characterized by emotional exhaustion, depersonalization, and reduced personal accomplishment. Emotional exhaustion arises as emotional resources are depleted, workers feel they are no longer able to give of themselves at a psychological level. Depersonalization occurs when workers develop negative cynical attitudes and feelings about one's clients. Reduced personal accomplishment refers to the tendency to evaluate oneself negatively, particularly in regard to one's work with clients. ${ }^{[11,12]}$

\subsection{Significance of the study}

Burnout is one of the challenges that many nurses are facing nowadays. The methods of prevention and confrontation of burnout concern the better planning of hospital, the enrichment of work, the inclusion of nurses in decision-making, the clarification of roles and duties of nurses, the opportunity given for continuing training and education which motivate them for more achievement. So, the main objective of the present research is to assess nurses' achievement motivation and its relation to their decision making ability, beliefs, and job burnout at obstetrics and gynecological departments.

\subsection{Aim of the study}

The study is aimed at assessing nurses' achievement motivation and its relation to their decision making ability, beliefs, and job burnout at obstetrics and gynecological departments through:

(1) Assessing nurses' achievement motivation at obstetrics and gynecological departments;

(2) Identifying nurses' decision making ability, and beliefs at obstetrics and gynecological departments;

(3) Determining nurses' job burnout level at obstetrics and gynecological departments;

(4) Finding out the relation between nurses' achievement motivation and their decision making ability, beliefs, and job burnout at obstetrics and gynecological departments.

\section{SUBJECTS AND METHODS}

\subsection{Research design}

A descriptive co-relational design was utilized to assess nurses' achievement motivation and its relation to their decision making ability, beliefs, and job burnout at obstetrics and gynecological departments.

\subsection{Setting}

This study was conducted in all obstetric and gynecological departments affiliated to ministry of health, in Port Said governorate, Egypt.

\subsection{Subjects}

The target population consisted of all staff nurses working in all obstetric and gynecological departments affiliated to ministry of health, in Port Said governorate, Egypt $(n=75)$, with at least one year experience in their work units. The 
studied nurses were female between 22 and 60 years old with mean age $38.5 \pm 11.7$, the majority of nurses were holding a nursing diploma, only $0.8 \%$ of the study sample have a bachelor degree. The highest percent of studied nurses (28\%) worked in the inpatient obstetric and gynecological care units, nearly quarter of nurses worked in the antenatal care and $24 \%$ of them worked in family planning, while $6.7 \%$ worked in normal labor and 5.3\% in ICU and emergency. Less than half of the nurses had between 20 and 30 years of experience in nursing with mean of $19.1 \pm 10.9$. Moreover, the highest percent of nurses $(45.3 \%)$ have experience in department between 10 and 20 years old with mean of $12.5 \pm 8.3$.

\subsection{Tools of data collection}

The researchers used four different tools for data collection. These were a self-administered questionnaire to assess nurses' achievement motivation and its relation to their decision making ability, beliefs and job burnout at obstetric and gynecological departments.

\subsection{Self-administered questionnaire: It is consisted of the following parts}

- Part I (personal and job characteristics): This part included questions about nurse's personal data and job characteristics such as work unit, age, nursing qualification, and years of experience.

- Part II (AMS). This part was developed by the researchers based on reviewing of related literatures. ${ }^{[13-15]}$ Is a 26-item self-evaluation scale that is used to measure the nurse's achievement motivation. The AMS is a 3-point Likert-type format. A positive content indicates the motive to achieve success (MS) statements from (1-15), while a negative content indicates the motive to avoid failure (MF) statements from (16-26).

- Part III (decision making beliefs questionnaire): This part was developed by Apdoon. ${ }^{[16]}$ It consists of 21 statement followed by 3 choices score is calculated according a key answer.

- Part IV (Decision making ability). This part was developed by Apdoon. ${ }^{[16]}$ It consists of 38 statement measured along five- point scales ranging from strongly agree $=(5)$ to strongly disagree $=(1)$.

- Part V (job burnout scale) developed originally by Maslach. ${ }^{[17]}$ The inventory contains 22 items that assess the three components of burnout. Emotional exhaustion was measured using nine items (e.g. "I feel like I'm at the end of my rope"); depersonalization was measured using five items (e.g. "I feel I treat some patients as if they were impersonal objects"); and per- sonal accomplishment was measured using eight items (e.g. 'I feel I'm positively influencing other people's lives through my work").

\subsection{Handling and analysis of data}

The raw data were coded and entered into SPSS system files (SPSS package version 20). Analysis and interpretation of data were conducted.

The following statistical measures were used:

- Descriptive statistics including frequency, distribution, mean, and standard deviation were used to describe different characteristics.

- Kolmogorov - Smirnov test was used to examine the normality of data distribution.

- Univariate analyses including: $t$-test and ANOVA test were used to test the significance of results of quantitative variables.

- Linear correlation using Pearson correlation coefficient was conducted to show scores of decision making abilities and beliefs with scores of job burnout and achievement motivation among the studied nurses.

- The significance of the results was at the $5 \%$ level of significance.

\subsection{Validity of tools}

The four tools were tested for clarity, relevance, applicability, comprehensiveness, understanding, and ease of implementation by a panel of seven nursing professors from various faculties of nursing, all of whom are specialists and experts in nursing management and administration. According to their opinion, minor modifications were made to the tools.

\subsection{Reliability of tools}

The tools were tested for reliability using Cronbach's alpha technique. The result for the AMS questionnaire was Cronbach's alpha $=0.754$, and for the decision making beliefs it equaled 0.905 , the decision making ability was 0.811 and job burnout scale equaled 0.998 .

\subsection{Field work}

This study was carried out in the period started from January 2016 to May 2017, and the data were collected by the researchers after obtaining an official agreement from director of studied settings. Meeting with the directors of nursing service was conducted by the individual basis to explain objectives of the study and to gain their cooperation.

\subsection{Individual interview}

Individual interview was carried out to assess knowledge of staff nurses regarding study variables. Each interview took 
a period of about 25-30 minutes. The data were collected two months starting from 1 June to 30 July; studied hospitals were visited for two days per week.

\subsection{Ethical consideration}

An official letter was sent from the Faculty of Nursing to study settings medical and nursing directors requesting their formal agreement to the study being carried out. The study was approved by the medical directors after checking the study proposal and tools. The aim of the study was explained to staff nurses who participated in the study; their consent to participate was obtained and they were assured about the confidentiality of the information gathered and assured that it will be used only for the purpose of the study. They were informed about their right to refuse or to withdraw at any time.

\section{RESUlts}

As shown in Table 1, which demonstrates achievement motivation among the nurses, the total mean score of motivation to achieve success was $77.8 \pm 9.6$. As the table shows, the highest percent of nurses (85.3\%) were agreed about (I do as much time as possible in order to improve my abilities in the field of specialty), followed by $82.7 \%$ were agreed about (If I do not figure out something in a task; I do all the efforts to improve my performance).

Table 1. Results of achievement motivation among the studied nurses

\begin{tabular}{|c|c|c|c|c|c|c|}
\hline \multirow{3}{*}{ Motivation to achieve success } & \multicolumn{6}{|c|}{ Response of the studied nurses $(n=75)$} \\
\hline & \multicolumn{2}{|c|}{ Disagree } & \multicolumn{2}{|c|}{ Uncertain } & \multicolumn{2}{|c|}{ Agree } \\
\hline & No. & $\%$ & No. & $\%$ & No. & $\%$ \\
\hline I accomplish the difficult tasks, even if I'm not confident that I will be able to accomplish it. & 24 & 32.0 & 21 & 28.0 & 30 & 40.0 \\
\hline If I do not figure out something in a task; I do all the efforts to improve my performance. & 0 & 0.0 & 13 & 17.3 & 62 & 82.7 \\
\hline $\begin{array}{l}\text { I prefer The work that is have clearly defined mission, provided that I set myself why and } \\
\text { how I work. }\end{array}$ & 1 & 1.3 & 13 & 17.4 & 61 & 81.3 \\
\hline I do as much time as possible in order to improve my abilities in the field of specialty. & 5 & 6.7 & 6 & 8.0 & 64 & 85.3 \\
\hline $\begin{array}{l}\text { I consider important and hard work is the work that is the probability of success is equal } \\
100 \% \text {. }\end{array}$ & 0 & 0.0 & 22 & 29.3 & 53 & 70.7 \\
\hline $\begin{array}{l}\text { It's very important for me to do the work at its best level even if it led to a collision with my } \\
\text { colleagues. }\end{array}$ & 19 & 25.3 & 16 & 21.4 & 40 & 53.3 \\
\hline In Leisure I exercise any game to develop my skills rather than to rest and entertainment. & 12 & 16.0 & 33 & 44.0 & 30 & 40.0 \\
\hline $\begin{array}{l}\text { I prefer to do something considered to be essential, even if there is a percentage of error of } \\
50 \% \text { rather the advice of others }\end{array}$ & 30 & 40.0 & 28 & 37.3 & 17 & 22.7 \\
\hline $\begin{array}{l}\text { If I had the choice, I would choose the work with low salary in beginning but there are } \\
\text { opportunities, and with my efforts the salary will increase as soon as possible. }\end{array}$ & 3 & 4.0 & 19 & 25.3 & 53 & 70.7 \\
\hline $\begin{array}{l}\text { After the completion of the evaluation process I tend to rest and recuperation more than a } \\
\text { joy to get a high evaluation. }\end{array}$ & 19 & 25.3 & 22 & 29.4 & 34 & 45.3 \\
\hline After failing I become more vibrant and alert to follow my work & 34 & 45.3 & 23 & 30.7 & 18 & 24.0 \\
\hline If there is doubt in the success of any beginning I prefer risk & 26 & 34.7 & 30 & 40.0 & 19 & 25.3 \\
\hline I like more the completion of a complex and unfamiliar tasks & 22 & 29.3 & 31 & 41.4 & 22 & 29.3 \\
\hline $\begin{array}{l}\text { When there is competition or initiative, I have interest and enthusiasm more than } \\
\text { discomfort }\end{array}$ & 6 & 8.0 & 17 & 22.7 & 52 & 69.3 \\
\hline $\begin{array}{l}\text { I prefer to work without mercy for myself until the moment that I become completely } \\
\text { satisfied of the results of my work }\end{array}$ & 18 & 24.0 & 16 & 21.3 & 41 & 54.7 \\
\hline$($ Mean $\pm S D)$ & 77.8 & & & & & \\
\hline
\end{tabular}

As indicated in Table 2, which demonstrates achievement motivation among the nurses, the total mean score of achievement motivation was $79.5 \pm 8.7$. Regarding motivation to avoid failure the mean score was $81.8 \pm 10.9$. As the table shows, the highest percent of nurses $(81.3 \%)$ were agreed about (During the evaluation I prefer the questions to be specific and in the area of specialization), followed by $72 \%$ were agreed about (If I should accomplish a complex task, I prefer to accomplish it in participation with other person).

As shown in Table 3, the mean decision making beliefs among the staff nurses was $(75.6 \pm 4.5)$. The highest good Published by Sciedu Press score observed was for the response of "When an individual cope with the problem $(89.3 \%)$ ", followed by the good response for capacity most relevant to the decision-maker (66.7) and Factors that affect the decision $64.0 \%$.

Table 4 presents the results pertaining to decision making ability among the staff nurses. As can be seen from the data, the total mean score for decision making ability was $74.2 \pm 7.3$. The table also reveals that $97.3 \%$ of all staff agreed up on that they gathering facts they need before making a decision and $96 \%$ of them agreed up on that they appreciate the responsibility of decision-making. 
Table 2. Results of achievement motivation among the studied nurses [CONT]

\begin{tabular}{|c|c|c|c|c|c|c|}
\hline \multirow{3}{*}{ Motivation to avoid failure } & \multicolumn{6}{|c|}{ Response of the studied nurses $(n=75)$} \\
\hline & \multicolumn{2}{|c|}{ Disagree } & \multicolumn{2}{|c|}{ Uncertain } & \multicolumn{2}{|c|}{ Agree } \\
\hline & No. & $\%$ & No. & $\%$ & No. & $\%$ \\
\hline $\begin{array}{l}\text { If I should accomplish a complex task, I prefer to accomplish it in participation with other } \\
\text { person }\end{array}$ & 1 & 1.3 & 20 & 26.7 & 54 & 72.0 \\
\hline I am attracted more to work that does not require effort and confident of its success & 20 & 26.7 & 20 & 26.6 & 35 & 46.7 \\
\hline During the evaluation I prefer the questions to be specific and in the area of specialization & 1 & 1.3 & 13 & 17.4 & 61 & 81.3 \\
\hline $\begin{array}{l}\text { I prefer choose the work with low possibility of failure, besides I can achieve great success } \\
\text { in it }\end{array}$ & 8 & 10.7 & 22 & 29.3 & 45 & 60.0 \\
\hline $\begin{array}{l}\text { When I accomplish the daily tasks, I'm being more worried from falling in any mistake } \\
\text { rather than how to submit it properly }\end{array}$ & 8 & 10.7 & 18 & 24.0 & 49 & 65.3 \\
\hline $\begin{array}{l}\text { When I do a difficult job, I'm afraid from being unable to do it than my hope to be } \\
\text { accomplished }\end{array}$ & 8 & 10.7 & 24 & 32.0 & 43 & 57.3 \\
\hline $\begin{array}{l}\text { I work more effectively under the command of other than take on a personal responsibility } \\
\text { to do something }\end{array}$ & 20 & 26.7 & 20 & 26.7 & 24 & 32.0 \\
\hline $\begin{array}{l}\text { I accomplish tasks that specifically raised the why and how being accomplished more } \\
\text { productively than tasks that are only in general lines }\end{array}$ & 8 & 10.7 & 20 & 26.6 & 34 & 45.3 \\
\hline $\begin{array}{l}\text { If I resolve any issue successfully I try again to resolve similar issue instead of moving to } \\
\text { resolve more difficult issue }\end{array}$ & 16 & 21.3 & 23 & 30.7 & 36 & 48.0 \\
\hline$($ Mean $\pm S D)$ & 81.8 & 10.9 & & & & \\
\hline Total achievement motivation Score $($ Mean $\pm S D)$ & 79.5 & & & & & \\
\hline
\end{tabular}

Table 3. Results of decision making beliefs among the studied nurses

\begin{tabular}{|c|c|c|c|c|c|c|}
\hline \multirow{3}{*}{ Decision making believes } & \multicolumn{6}{|c|}{$\mathrm{n}=75$} \\
\hline & \multicolumn{2}{|c|}{ Poor } & \multicolumn{2}{|c|}{ Moderate } & \multicolumn{2}{|c|}{ Good } \\
\hline & No. & $\%$ & No. & $\%$ & No. & $\%$ \\
\hline The real reason behind taking a successful decision & 23 & 30.7 & 48 & 64.0 & 4 & 5.3 \\
\hline When an individual cope with the problem & 1 & 1.3 & 7 & 9.4 & 67 & 89.3 \\
\hline Difficulties faced by the individual when making decision & 22 & 29.3 & 22 & 29.4 & 31 & 41.3 \\
\hline When an individual faces the problem work firstly on & 5 & 6.7 & 51 & 68.0 & 19 & 25.3 \\
\hline Capacity most relevant to the decision-maker & 14 & 18.7 & 11 & 14.6 & 50 & 66.7 \\
\hline The most important stages of the decision-making & 40 & 53.3 & 21 & 28.0 & 14 & 18.7 \\
\hline When making a decision the individual must care about & 36 & 48.0 & 25 & 33.3 & 14 & 18.7 \\
\hline Personal skills of the decision-maker is the ability to & 43 & 57.3 & 5 & 6.7 & 27 & 36.0 \\
\hline I believe that the appropriate method to take decision & 38 & 50.7 & 21 & 28.0 & 16 & 21.3 \\
\hline Individual implement decisions by & 33 & 44.0 & 29 & 38.7 & 13 & 17.3 \\
\hline How do you facing differences between individuals you take with them the decision & 29 & 38.7 & 23 & 30.6 & 23 & 30.7 \\
\hline What are the main elements of the decision & 68 & 90.7 & 2 & 2.6 & 5 & 6.7 \\
\hline What individual do to gather information about the problem & 61 & 81.3 & 9 & 12.0 & 5 & 6.7 \\
\hline The process of selecting the solution to the problem affected by & 26 & 34.7 & 33 & 44.0 & 16 & 21.3 \\
\hline Managerial position affects the decision-making & 9 & 12.0 & 39 & 52.0 & 27 & 36.0 \\
\hline The reason that individual decides to gather information for it & 42 & 56.0 & 10 & 13.3 & 23 & 30.7 \\
\hline Do you think that the discussion of the method of decision-making must be & 44 & 58.7 & 5 & 6.6 & 26 & 34.7 \\
\hline When an individual has a problem and is forced to make a decision & 17 & 22.7 & 49 & 65.3 & 9 & 12.0 \\
\hline I have the opportunity to participate in making decisions & 28 & 37.3 & 46 & 61.4 & 1 & 1.3 \\
\hline$($ Mean $\pm S D)$ & 75.6 & & & & & \\
\hline
\end{tabular}


Table 4. Results of decision making ability among the studied nurses

\begin{tabular}{|c|c|c|c|c|c|c|}
\hline \multirow{3}{*}{ Decision making believes } & \multicolumn{6}{|c|}{ Response of the studied nurses $(n=75)$} \\
\hline & \multicolumn{2}{|c|}{ SD/Disagree } & \multicolumn{2}{|c|}{ Uncertain } & \multicolumn{2}{|c|}{ Agree/SA } \\
\hline & No. & $\%$ & No. & $\%$ & No. & $\%$ \\
\hline I have the ability to choose the most appropriate time to make a decision & 3 & 4.0 & 10 & 13.3 & 62 & 82.7 \\
\hline I have the enough experience and educational degree to make the successful decision & 3 & 4.0 & 19 & 25.3 & 53 & 70.7 \\
\hline I build my decisions based on the knowledge of the facts & 1 & 1.3 & 3 & 4.0 & 71 & 94.7 \\
\hline When I made the decision, I following the implementation of it very well & 1 & 1.3 & 3 & 4.0 & 71 & 94.7 \\
\hline I can recognize the problem & 0 & 0.0 & 7 & 9.3 & 68 & 90.7 \\
\hline I realized the importance of timing in the decision making & 0 & 0.0 & 8 & 10.7 & 67 & 89.3 \\
\hline I gathering facts that I need before making a decision & 0 & 0.0 & 2 & 2.7 & 73 & 97.3 \\
\hline I weigh the consequences of the decision & 0 & 0.0 & 4 & 5.3 & 71 & 94.7 \\
\hline I appreciate the responsibility of decision-making & 0 & 0.0 & 3 & 4.0 & 72 & 96.0 \\
\hline I am responsible for the failure of wrong decision & 6 & 8.0 & 7 & 9.3 & 62 & 82.7 \\
\hline I refer to the regulations and laws to guide me when making a decision & 1 & 1.3 & 4 & 5.4 & 70 & 93.3 \\
\hline I determine pros and cons of the decision & 0 & 0.0 & 6 & 8.0 & 69 & 92.0 \\
\hline I follow the decision & 1 & 1.3 & 4 & 5.4 & 70 & 93.3 \\
\hline I consider myself being engaged in discussions constantly to make the decision & 3 & 4.0 & 11 & 14.7 & 61 & 81.3 \\
\hline When making a decision I measure attitudes based on previous experiences & 4 & 5.3 & 6 & 8.0 & 65 & 86.7 \\
\hline $\begin{array}{l}\text { I would estimate the proportion of individuals who are involved in the discussions at the } \\
\text { decision-making }\end{array}$ & 2 & 2.7 & 16 & 21.3 & 57 & 76.0 \\
\hline I rule out solutions that collide with the laws and regulations that cannot be changed & 4 & 5.3 & 18 & 24.0 & 53 & 70.7 \\
\hline $\begin{array}{l}\text { I can identify situations that have great weight for the opinion of all the individuals } \\
\text { involving in the decision-making }\end{array}$ & 3 & 4.0 & 18 & 24.0 & 54 & 72.0 \\
\hline I rely on personal contact when the decision was taken & 14 & 18.7 & 8 & 10.6 & 53 & 70.7 \\
\hline $\begin{array}{l}\text { I Exempted participants in the decision-making from the responsibility of the consequences } \\
\text { of this decision }\end{array}$ & 21 & 28.0 & 14 & 18.7 & 40 & 53.3 \\
\hline To know the opinion of the group in writing takes a long time & 10 & 13.3 & 12 & 16.0 & 53 & 70.7 \\
\hline Members' ire raises when the leader distinguish one member publicly for his proposal & 10 & 13.3 & 14 & 18.7 & 51 & 68.0 \\
\hline Talking privately with other is a way to get their opinion frankly about the problem & 15 & 20.0 & 7 & 9.3 & 53 & 70.7 \\
\hline $\begin{array}{l}\text { I faced the differences in the tendencies and trends of individuals through the development } \\
\text { of general principles }\end{array}$ & 4 & 5.3 & 15 & 20.0 & 56 & 74.7 \\
\hline Calm discussion style leads to convincing others with the mental and logical arguments & 1 & 1.3 & 4 & 5.5 & 70 & 93.3 \\
\hline Phone calls reveal a meeting to take decision & 16 & 21.3 & 14 & 18.7 & 45 & 60.0 \\
\hline Scarcity of information due to the difficulty of knowing it accurately and quickly & 3 & 4.0 & 16 & 21.3 & 56 & 74.7 \\
\hline $\begin{array}{l}\text { I consider a leader waiver of his ideas and the acceptance of the proposal by the others a } \\
\text { sign of weakness }\end{array}$ & 16 & 21.3 & 8 & 10.7 & 51 & 68.0 \\
\hline I go back again to my decisions taken & 41 & 54.7 & 19 & 25.3 & 15 & 20.0 \\
\hline Scarcity of information since it is expensive & 30 & 40.0 & 19 & 25.3 & 26 & 34.7 \\
\hline I delay decision making hoped that something happens comforting me from it & 40 & 53.3 & 16 & 21.4 & 19 & 25.3 \\
\hline I allow for previous opinions to affect my decisions & 27 & 36.0 & 22 & 29.3 & 26 & 34.7 \\
\hline I hesitate when deciding & 20 & 26.7 & 16 & 21.3 & 39 & 52.0 \\
\hline Most of the decisions implemented is the result of my decisions & 36 & 48.0 & 23 & 30.7 & 16 & 21.3 \\
\hline My psychological status affect the result of my decisions & 31 & 41.3 & 15 & 20.0 & 29 & 38.7 \\
\hline I back down in my decision after I take it & 19 & 25.3 & 12 & 16.0 & 44 & 58.7 \\
\hline When I take decision I suffer publicly doubt from his fault or his senses & 23 & 30.7 & 21 & 28.0 & 31 & 41.3 \\
\hline I allow the intolerance and bias to affect my decisions & 18 & 24.0 & 7 & 9.3 & 50 & 66.7 \\
\hline Mean $\pm S D$ & 74.2 & & & & & \\
\hline
\end{tabular}

Table 5. Scores of subscales of burnout among the studied nurses

\begin{tabular}{ll}
\hline \multirow{2}{*}{ Job burnout subscales $(\%)$} & Studied nurses $(\mathbf{n}=\mathbf{7 5})$ \\
\cline { 2 - 2 } & $($ Mean $\pm \boldsymbol{S D})$ \\
\hline Emotional exhaustion score & $56.5 \pm 12.3$ \\
depersonalization score & $49.6 \pm 8.8$ \\
Personal accomplishments score & $89.8 \pm 8.6$ \\
Total score & $50.2 \pm 7.3$ \\
\hline
\end{tabular}

As shown in Table 5, the majority of nurses evaluated in this study $(89.8 \pm 8.6)$ achieved high scores on their personal accomplishments. Meanwhile, $56.5 \pm 12.3$ of them have emotional exhaustion followed by $49.6 \pm 8.8$ have depersonalization.

Correlation between scores of achievement motivation with decision making abilities, beliefs and scores of job burnout among the studied nurses are shown in Table 6. As can be 
seen from the results, there is significant correlation between Achievement motivation and decision making ability while no statistically significant correlation was detected between achievement motivation and decision making beliefs and total score of job burnout whereas, emotional exhaustion and personal accomplishments are significantly correlated with achievement motivation $p \leq .05$.

Table 7 delineates the correlation between personal and job characteristics of the studied nurses and their scores at different parameters. The results reveal significant correlation between nurses' marital status and decision ability, as well as there is significant correlation between nurses' educational qualification and motivation. Also, significant correlation was found between nurses' department of employment and motivation $p \leq .05$.

\section{Discussion}

Achievement motivation was defined as the desire for accomplishment and mastery of skills. ${ }^{[18]}$ Achievement motivation is the striving to increase or to keep as high as possible, one's own capabilities in all activities in which a standard of excellence is thought to apply and where the execution of such activities can, therefore either succeed or fail. ${ }^{[2]}$ Findings of the present study reveals that more than three quarters of nurses have achievement motivation, the total mean score of motivation to achieve success was $77.8 \pm 9.6$, the highest percent of nurses who have motivation to achieve success were agreed about that they do as much time as possible in order to improve their abilities in the field of specialty, followed by who were agreed about. If they don't figure out something in a task; they do all the efforts to improve their performance. Moreover, the total mean score of motivation to avoid failure was $81.8 \pm 10.9$, the highest percent of nurses were agreed about that during the evaluation they prefer the questions to be specific and in the area of specialization, followed by if they should accomplish a complex task, and they prefer to accomplish it in participation with other person.

Table 6. Correlation between scores of achievement motivation with decision making abilities, beliefs and scores of job burnout among the studied nurses

\begin{tabular}{|c|c|c|c|c|c|c|}
\hline \multirow{3}{*}{ Scales } & \multicolumn{6}{|c|}{ Achievement motivation scale $(n=75)$} \\
\hline & \multicolumn{2}{|c|}{ Motivation to achieve success } & \multicolumn{2}{|c|}{ Motivation to avoid failure } & \multicolumn{2}{|c|}{ Total score } \\
\hline & $r$ & $p$ & $r$ & $p$ & $r$ & $p$ \\
\hline Decision making believes & -0.105 & .370 & 0.008 & .942 & -0.063 & .594 \\
\hline Decision making ability & 0.260 & $.024^{*}$ & 0.196 & .092 & 0.272 & $.018^{*}$ \\
\hline \multicolumn{7}{|l|}{ Job burnout scale } \\
\hline - Emotional exhaustion score $\%$ & 0.243 & $.035^{*}$ & 0.341 & $.006^{*}$ & 0.324 & $.005^{*}$ \\
\hline - Depersonalization score $\%$ & 0.233 & $.044^{*}$ & -0.022 & .851 & 0.137 & .240 \\
\hline - Personal accomplishments score \% & 0.369 & $.001^{*}$ & 0.004 & .971 & 0.238 & $.040^{*}$ \\
\hline - Total score of job burnout $\%$ & 0.074 & .529 & 0.210 & .071 & 0.159 & .172 \\
\hline
\end{tabular}

Note. $r$ : Pearson correlation coefficient; ${ }^{*}$ significant at $p \leq .05$

Table 7. Relation between personal and job characteristics of the studied nurses and their scores at different parameters

\begin{tabular}{|c|c|c|c|c|c|c|c|c|c|}
\hline \multirow{2}{*}{$\begin{array}{l}\text { Personal and job } \\
\text { characteristics }\end{array}$} & \multirow{2}{*}{$\mathbf{n}$} & \multicolumn{2}{|c|}{ Job burnout } & \multicolumn{2}{|c|}{ Decision believes } & \multicolumn{2}{|c|}{ Decision ability } & \multicolumn{2}{|c|}{ Motivation } \\
\hline & & Mean $\pm S D$ & Sig & Mean $\pm S D$ & Sig & Mean $\pm S D$ & Sig & Mean $\pm S D$ & Sig \\
\hline \multicolumn{10}{|l|}{ Marital status } \\
\hline - Not married & 11 & $52.8 \pm 8.2$ & $t=1.261$ & $76.1 \pm 2.9$ & $t=0.341$ & $79.8 \pm 9.1$ & $t=2.876$ & $81.9 \pm 8.6$ & $t=1.016$ \\
\hline - Married & 64 & $49.8 \pm 7.1$ & $p=.211$ & $75.5 \pm 4.8$ & $p=.734$ & $73.3 \pm 6.6$ & $p=.005^{*}$ & $79.1 \pm 8.7$ & $p=.313$ \\
\hline \multicolumn{10}{|l|}{ Educational qualification } \\
\hline - Nursing school diploma & 58 & $50.1 \pm 7.3$ & $F=0.075$ & $75.2 \pm 4.6$ & $F=1.178$ & $74.2 \pm 7.1$ & $F=0.256$ & $77.8 \pm 7.9$ & $F=5.295$ \\
\hline - Nursing institute & 11 & $50.9 \pm 6.5$ & $p=.928$ & $77.5 \pm 3.6$ & $p=.314$ & $75.1 \pm 7.9$ & $p=.775$ & $84.5 \pm 9.8$ & $p=.007^{*}$ \\
\hline - Faculty of nursing & 6 & $49.8 \pm 10.0$ & & $75.9 \pm 5.1$ & & $72.5 \pm 9.6$ & & $86.3 \pm 8.2$ & $\mathrm{D}, \mathrm{I}^{*}$ \\
\hline \multicolumn{10}{|l|}{ Department of employment } \\
\hline - Family planning & 18 & $53.7 \pm 6.7$ & $F=2.047$ & $75.3 \pm 5.5$ & $F=0.835$ & $74.5 \pm 7.3$ & $F=1.536$ & $78.4 \pm 6.8$ & $F=2.524$ \\
\hline - Antenatal care & 19 & $49.3 \pm 6.7$ & $p=.083$ & $74.2 \pm 3.9$ & $p=.529$ & $73.5 \pm 7.2$ & $p=.190$ & $76.9 \pm 8.8$ & $p=.037^{*}$ \\
\hline - Operation & 8 & $46.4 \pm 7.9$ & & $77.2 \pm 4.8$ & & $70.7 \pm 5.0$ & & $82.4 \pm 8.1$ & \\
\hline - Ward & 21 & $49.3 \pm 6.7$ & & $75.9 \pm 4.4$ & & $74.7 \pm 7.5$ & & $78.3 \pm 9.7$ & \\
\hline - Normal labor & 5 & $46.9 \pm 9.5$ & & $77.8 \pm 2.7$ & & $73.2 \pm 6.5$ & & $84.9 \pm 3.8$ & \\
\hline - Others & 4 & $54.9 \pm 7.6$ & & $76.2 \pm 4.1$ & & $82.5 \pm 8.7$ & & $90.4 \pm 6.2$ & \\
\hline
\end{tabular}

Note. $t$ : Student $t$-test; F: ANOVA test; "significant at $p \leq .05 ; \mathrm{D}, \mathrm{I}^{*}$ : Significant difference between Diploma and institute education by Bonferroni post hoc test; N.B. no correlation exist with these characteristics (age, duration of nursing experience, duration of experience in department) 
This findings could be due to that delivery of good quality nursing care is the fundamental role of nurses in obstetric and gynecological departments; the nurses well trained about determining what kind of care should be offered and what is needed by women with difficulties or complications arising during pregnancy or birth, the frequency of visits, what should actually be offered in terms of care for the women at each visit and what screening tests are necessary. This interpretation could be agreed upon with Schmalt ${ }^{[19]}$ who proposed that motivation to achieve Success, comprised of positive competence expectancies, desire to achieve, and behavior aimed at managing complicated tasks. Thus, motivation to achieve success corresponded to mastery and performanceapproach goals. In this regard, Tripathi and Cervone ${ }^{[20]}$ noted that achievement motivation differs with individual's working experience, as well as for people working in different cultures. Achievement motivated nurses prefer to work on a problem rather than leaving the outcome to chance. It is also seen that achievement motivated nurses seem to be more concerned with their personal achievement rather than the rewards of success. It is generally seen that achievement motivated nurses evidenced a significantly higher rate of advancement in their work compared to others. ${ }^{[2]}$

Many are encouraging the implementation of the increased decisional involvement of the nurses into the organization to enhance the culture of the nursing practice environment, the satisfaction with work, and the quality of patient care; to ameliorate the crisis. Citing nursing's constant surveillance of the patients and the need for efficient operations of the healthcare organizations, for decades nursing and organizational experts have advocated that professional nurses must be more involved in decisions that have an impact on patient care, working conditions, and the organizational policy. ${ }^{[21]}$

Regarding decision making beliefs among the staff nurses findings declare that more than three quarters of nurses have good beliefs about decision making. The highest good score observed was for the response of (When an individual cope with the problem), followed by the good response for capacity most relevant to the decision-maker and Factors that affect the decision. Moreover, findings pertaining to decision making ability among the staff nurses indicated the total mean score for decision making ability was 74.2 \pm 7.3 . The table also reveals that most staff nurses had a high agreement upon gathering facts they need before making a decision and they agreed up on that they appreciate the responsibility of decision-making.

This foregoing present study finding could be due to that obstetric and gynecological nurses regularly made decisions related to providing psychological support and teaching of mothers and family, providing basic nursing care included giving bed baths, monitoring blood pressure, patient observation, providing pressure area care and other nursing interventions common in obstetrics and gynecology. ${ }^{[4]}$ Nurses are increasingly regarded as key decision makers within the healthcare team. ${ }^{[22]}$ They are also expected to use the best available evidence in their judgments and decisions. The prescriptive model of evidence based decision making and the search-appraise-implement process that accompanies it is an active process. The results of Jaafarpour et al. ${ }^{[23]}$ who studied The participation of nurses in decision making provided support for decisional involvement of nurses.

Increasing the decisional involvement of the nurses also responds to the recommendations made 20 years ago by three "blue ribbon" panels to address the same work environment issues which are confronted by the practicing nurses today. The recommendations from these three classic studies encourage increasing nursing involvement in decision-making to strengthen the patients, the professionals, and the organizational well-being. ${ }^{[24]}$ Creating decisional involvement in work environments for the professional nursing practice is an exciting organizational strategy that holds promise for reducing job burnout and job dissatisfaction in healthcare settings. The results of this study highlight the importance of such organizational change efforts. ${ }^{[23,25]}$

Another main objective of the present study was to assess nurses' job burnout. The findings were alarming, nearly half of nurses evaluated in this study have burnout. More than half of them have emotional exhaustion and less than half have depersonalization. On the other hand, more than three quarters have personal accomplishments. This finding could be related to shift work, workload, role clarity and ambiguity as shown to be stressful factors among staff nurses in obstetric and gynecological units. In congruence with these present study findings, ${ }^{[26]}$ in a study in Lebanese, found that Nurses were reported moderate levels of burnout. As well as, findings of Lin et al. ${ }^{[27]}$ showed moderate levels of Emotional Exhaustion and Personal Accomplishment, and low levels Depersonalization.

Moreover, Findik ${ }^{[28]}$ highlighted that nurses in his study experience an average level of burnout, it was determined that the levels of emotional exhaustion were average, the levels of depersonalization were low, and the levels of personal accomplishments were high. Similar results were investigated nurses' burnout levels; In their study about burnout of nursing personnel in a regional university hospital, Malliarou et al. ${ }^{[29]}$ stated that level of burnout in the nursing personnel of a Regional University Hospital oscillated in mediocre levels; They presents emotional exhaustion, which is related 
with the shifts, depersonalization which is related with the hindrance of interdisciplinary collaboration and finally both of them influence the decision to abandon the specific working environment. Finally, the decreased sense of personal accomplishments leads to feelings of decreased social award of the nursing profession.

In a study by Niasar et al., ${ }^{[30]}$ which investigated burnout in operating room nurses, it was determined that $50.6 \%-96.5 \%$ of the participants experienced emotional exhaustion, $63.5 \%-89.3 \%$ experienced depersonalization, and $10 \%$ experienced a lack of personal accomplishments. Circenis et al. ${ }^{[31]}$ investigated levels of burnout, depression, and anxiety in surgical and operating room nurses and found that $46 \%$ of the participants demonstrated emotional exhaustion, $40 \%$ demonstrated depersonalization, and $42 \%$ demonstrated decreased personal accomplishments. Moustaka, et al. ${ }^{[32]}$ determined the work-related burnout levels of nurses to be on an average level.

In examining the relation between nurses' achievement motivation and their decision making ability and job burnout findings of the study showed a significant correlation between achievement motivation and decision making ability while no statistically significant correlation was detected between achievement motivation and decision making beliefs and total score of job burnout $p \leq .05$. Moreover, findings determined significant correlation between nurses' marital status and decision ability, as well as there is significant correlation between nurses' educational qualification and achievement motivation. Also, significant correlation was found between nurses' department of employment and motivation $p \leq .05$.

\section{Implications of the study}

Health care administrators, should address the factors that contribute to nurses' achievement motivation, decision making, and job burnout and try to cope with them by developing and applying supportive policies and practices; The placement of suitable nurse in the suitable place, The clarification of nurses' role and duties and their inclusion in the decisionmaking, the possibility of breaks and special authorizations given by administration, the operation of teams for psychological support, providing life-long learning for knowledge and risk of treatments. A focus on meeting the personal and professional needs of the nursing care is paramount if quality health care services are to continue. Continuous support of nurses through regular and periodic meeting is suggested, with constructive feedback, as well as disciplinary actions for defaulters and rewards for good achievers of the nurses. An important aspect that needs to be addressed is increasing continuing education programs for nurses, especially programs that deal with achievement motivation, decision making, and job burnout that enhance personal and professional skills and accomplishments.

\section{Conclusions}

Within a sample consisting of mostly diploma-holding nurses in the obstetric and gynecological setting of Port Said governorate, Egypt. The findings determined that more than three quarters of nurses have achievement motivation, more than three quarters of nurses have well beliefs about decision making, the total mean score for decision making ability was $74.2 \pm 7.3$. Nearly half of nurses evaluated in this study have burnout. More than half of them have emotional exhaustion and less than half have depersonalization. On the other hand, more than three quarters have personal accomplishments. There is significant correlation between achievement motivation and decision making ability while no statistically significant correlation was detected between achievement motivation and decision making beliefs and total score of job burnout whereas, emotional exhaustion and personal accomplishments are significantly correlated with achievement motivation.

\section{Recommendations}

This study therefore indicates employing the following strategies to process study variables more deeply:

- The placement of suitable professional in the suitable place, the clarification of professionals' role and duties and their inclusion in the decision-making. The possibility of breaks and special authorizations given by administration, and the increase of possibilities for professional development may increases nurses' achievement motivation.

- The operation of teams for psychological support evidence based policies aimed at creating better work environments where nurses feel more secure and have adequate resources to successfully perform their jobs, hence improving their health outcomes as well as that of their patients.

- Achievement motivation, decision making, and job burnout in the nurse practice environment is a dynamic conceptual process affect patient outcomes. Nurses need to call upon ways of knowing to make sound decisions and should be self-reflective.

- Creating decisional involvement in work environments for the professional nursing practice is an exciting organizational strategy that holds promise for reducing job burnout.

- Continuing nursing education and staff development activities are urgently needed to improve nurses' knowledge and skills concerning achievement motivation, and decision making.

ISSN 2324-7940 E-ISSN 2324-7959 
- The nursing schools' curricula should give more emphasis to achievement motivation, decision making.

- Further research is proposed to assess the impact of on-the-job training and application of achievement motivation, decision makingc.

\section{CONFLICTS OF INTEREST DISCLOSURE}

The authors declare they have no conflict of interest.

\section{REFERENCES}

[1] Zenzen TG. Achievement motivation, A Research Paper. The Graduate College, University of Wisconsin-Stout; 2002.

[2] Esteem S, Physiological S. Some Definitions of Achievement Motivation. Culture. 2013; 76-77.

[3] Singh K. Study of Achievement Motivation in Relation to Academic Achievement of Students. International Journal of Educational Planning \& Administration. 2011; 1(2): 161-171.

[4] Bakalis NA, Watson R. Nurses' decision-making in clinical practice. Nursing Standard. 2005; 19(23): 33-39. PMid: 28091011. https://doi.org/10.7748/ns.19.23.33.s48

[5] Tanner CA. Thinking like a nurse: A research- based model of clinical judgment in nursing. Journal of Nursing Education. 2006; 45(6): 204-211. PMid: 16780008 .

[6] Lauri S, Salanterä S, Chalmers K, et al. An exploratory study of clinical decision-making in five countries. Journal of Nursing Scholarship. 2001; 33(1): 83-90. PMid: 11253589. https://doi.org/10.111 $1 / \mathrm{j} \cdot 1547-5069.2001 .00083 . \mathrm{x}$

[7] Rashotte J, Carnevale FA. Medical and nursing clinical decision making: A comparative epistemological analysis. Nursing Philosophy. 2004; 5(2): 160-174. PMid: 15189556. https://doi.org/10.1 111/j.1466-769X. 2004.00175.x

[8] Pearson H. Science and intuition: Do both have a place in clinical decision making? British Journal of Nursing. 2013; 22(4): 212-215. PMid: 23448983. https://doi.org/10.12968/bjon.2013.22. 4.212

[9] Freudenberg HJ. Staff burnout. Journal of Social Issues. 1974; 30(1): 159-165. https://doi.org/10.1111/j.1540-4560.1974.tb0 0706.x

[10] Patrick K, Lavery JF. Burnout in nursing. Australian Journal of Advanced Nursing. 2007; 24(3): 43-48. PMid: 17518165.

[11] Maslach C, Leiter MP. REVERSING BURNOUT: How to rekindle your passion for your work. 2005

[12] Maslach C, Jackson S, Leiter MP. Making a significant difference with burnout inter- ventions: Researcher and practitioner collaboration. Journal of Organizational Behavior. 2012; 33: 296-300. https://doi.org/10.1002/job.784

[13] Lang JWB, Fries S. A revised 10-item version of the Achievement Motives Scale: Psychometric properties in German-speaking samples. European Journal of Psychological Assessment. 2006; 22: 216-224.

[14] Smith RL. A Contextual Measure of Achievement Motivation: Significance for Research in Counseling. VISTAS Online. 2015; 1(14): $1-11$.

[15] Zhang ZJ, Zhang CL, Zhang XG, et al. Relationship between selfefficacy beliefs and achievement motivation in student nurses. Chinese Nursing Research. 2015; 2(2-3): 67-70.

[16] Apdoon (1999): in Mosbeh MA (2011). The ability of decisionmaking and its relationship to both of the effectiveness and social support among the educational counselors in governmental schools in Gaza governorates [published master thesis]. Faculty of education. EL-Azhar University. Available from: www . alazhar .edu.ps/Lib rary/aattachedFile.asp?id_no $=0045888$
[17] Maslach C. The cost of caring, Englewood Cliffs, New Jersy, PrenticeHall Inc; 1982.

[18] Young MJ, Chen N, Morris MW. Belief in stable and fleeting luck and achievement motivation. Personality and Individual Differences. 2009; 47: 150-154. https://doi.org/10.1016/j.paid. 2009. 02.009

[19] Schmalt HD. Validity of a Short Form of the Achievement-Motive Grid (AMG-S): Evidence for the Three-Factor Structure Emphasizing Active and Passive Forms of Fearof Failure. Journal of Personality Assessment. 2005; 84: 172-185. PMid: 15799892. https : //doi.org/10.1207/s15327752jpa8402_07

[20] Tripathi R, Cervone D. Cultural variations in achievementmotivation despite equivalent motivational strength: motivationalconcerns among Indian and American corporate professionals. Journal of Research in Personality. 2008; 42(2): 456-464. https ://doi .org/10 $.1016 / j \cdot j r p .2007 .06 .001$

[21] Havens DS, Vasey J. The staff nurse decisional involvement scale. Nursing research. 2005; 54(6): 376-383. https://doi .org/10.1 097/00006199-200511000-00003

[22] Need I, Making CD, Underpinning M, et al. EBN notebook. 2006; 68-73.

[23] Jaafarpour M, Khani A. The participation of nurses in decision making. Journal of Clinical and Diagnostic Research. 2011; 5(1): 16-19.

[24] Marisa K, Mary A. Benefits and outcomes of staff nurses' participation in decision making. J Nurs Adm. 2001; 31(1): 16-23. https://doi.org/10.1097/00005110-200101000-00005

[25] Sabbah I. Burnout among Lebanese nurses: Psychometric properties of the Maslach Burnout Inventory-Human Services Survey (MBIHSS). Health. 2012; 4(9): 644-652. https ://doi.org/10.4236/ health.2012.49101

[26] Lin F, St John W, McVeigh C. Burnout among hospital nurses in China. Journal of Nursing Management. 2009; 17(3): 294-301. PMid: 21456318. https://doi.org/10.1111/j.1365-2834.2008.0 0914. $\mathrm{x}$

[27] Johansen ML, O’Brien JL. Decision Making in Nursing Practice: A Concept Analysis. Nursing Forum. 2016; 51(1): 40-48. PMid: 25639525. https://doi.org/10.1111/nuf . 12119

[28] Findik UY. Operating Room Nurses' Burnout and Safety Applications. 2015; 8(3): 610-617.

[29] Malliarou MM, Moustaka EC, Konstantinidis TC. Burnout of nursing personnel in a regional university hospital. Health Science Journal. 2008; 2: 140-152. Available from: http://search.ebscohost.com/login. aspx?direct=tru e\&db $=$ cin20\&AN $=2010019362 \&$ site $=$ ehost - live

[30] Moustaka E, Malliarou M, Sarafis P, et al. Burnout in nursing personnel in a regional university hospital. Balkan Military Medical Review. 2009; 12(1): 1-7.

[31] Niasar NK, Kharame TZ, Koohbor M, et al. Professional burnout and the affecting factors in operating room nurses in Qom teaching hospitals. Jentashapir J Health Res. 2013; 4(4): 305-314.

[32] Circenis K, Millere I, Deklava L. Stress- related psychological disorders among surgical are nurses in Latvia. Review of Global Medicine And Healthcare Research (RGMHR). 2011; 2(2): 131-138. 